\title{
Teaching Dollar-Cost Averaging: An In-Class Student Team Simulation
}

\author{
Brian Porter \\ Hope College
}

This paper presents a class tested exercise requiring student teams to perform investing decisions with the objective of maximizing the portfolio value. Afterwards, dollar-cost averaging (DCA) is introduced and usually achieves a greater portfolio value than that of most teams. Students are then assigned the task of determining the lowest and highest possible portfolio values for the simulation. DCA is then assessed on its nearness to either the worst or best (optimal) value. The exercise is enjoyable for students and offers several points of learning, including that DCA is an attractive investing strategy that offers many benefits and performs well.

Keywords: Investing, Retirement Planning, Dollar-Cost Averaging, Pedagogy, Simulation

\section{INTRODUCTION}

Approximately 10,000 people in the United States retire every day (Kessler, 2014). In previous generations defined benefit retirement plans were the standard. With such plans, employers, not employees, assumed most of the risk during the wealth building years of employment. Once retired, former employees received regular retirement payments. Again, little risk or choice was required of the employee. In 1980, a tide change was instigated when Ted Benna implemented the first 401(k) employee savings plan for his employees at Johnson Company (Porter, 2017). Previously, 401(k) plans had been strictly used to benefit higher level employees, not ordinary workers. A trend began with defined contribution retirement plans becoming more popular as defined benefit retirement plans were phased out. From 1983 to 2016 the percent of workers covered by defined benefit pensions has dropped from 62 percent to 17 percent (Rattner, 2018). Today 401(k) accounts are the most common employer-sponsored retirement plan and the number of people investing for retirement continues to grow. Increasingly, even people with little finance and investing knowledge are being forced to save and invest for retirement.

Students that go on to work in the private sector will likely have defined contribution retirement plans and consequently be making investment decisions. Overconfidence is a well-established feature of human nature and may give students the false notion that active trading is the superior investment strategy (Thaler, 2015). Warren Buffett, one of the most astute investors of our time, discourages active trading and recently won a $\$ 1$ million wager pitting the passive S\&P 500 against actively managed hedge funds (McDonald, 2017). Buffett estimates that over the past decade pension funds, endowments, and individuals have lost over $\$ 100$ billion to hedge funds and money managers that charge exorbitant fees (Sorkin, 2017).

Journal of Higher Education Theory and Practice Vol. 19(4) 2019129 
John Bogle, the founder of the Vanguard Group of Investment Companies was a strong advocate of simple investing and scornful of frequent trading with its associated high fees. Bogle believed that "In investing, you get what you don't pay for. Costs matter. Intelligent investors will use low-cost index funds and will stay the course. They won't be foolish enough to think that they can consistently outsmart the market" (Wyatt, 2019).

Because of students' limited knowledge and misperceptions of retirement plans and investing strategies, exposure and education pertaining to retirement planning is prudent. Dollar-cost averaging (DCA) is a simple passive investing technique that should serve students well as future investors. This paper will offer a class tested participatory simulation involving teams, with a follow up exercise, which persuasively demonstrates to students the advantages of DCA. As Campbell (2016) has observed, numerous studies indicate that simulations and experiential exercises positively impact student learning (Cebula and Toma, 2002; Pyane and Tanner, 2011; Seaton and Boyd, 2008). The experiential exercise proposed in this paper is ideally suited for a variety of classes (Introduction to Finance, Personal Investments, etc.) and has the potential to positively impact students and their future lives.

\section{OVERVIEW OF IN-CLASS SIMULATION}

Student teams of two to four are ideal and work well. Teams larger than four may result in some students participating less and free riding. Each student is provided with a template to track their team's investing and portfolio value (Appendix 1).

Students are instructed that the experiential simulation is their soon to be reality. Once they graduate and begin working they will need to be investing for their future (e.g., retirement). The following introductory instructions are offered to students:

1. Students are to assume they are working and saving for retirement.

2. Periodically (e.g., every three months) teams receive $\$ 1,000$ to invest. This represents money students earn from working and will invest for retirement.

3. Teams are to invest with the objective of achieving the highest portfolio dollar value.

4. Each team will be competing against other teams.

5. For simplicity, each period the students have the possibility of investing in only one diversified investment (e.g., a broad market index fund such as the Vanguard S\&P 500, VFINX).

6. After the professor gives the investment price for a period (along with an explanation for the price change), students have one of three possibilities: (a) Purchase shares of the security, (b) Sell shares of the security, or (c) Deposit the entire $\$ 1,000$ into cash.

7. Students are allowed to purchase partial shares of the investment (similar to a mutual fund).

8. Before decisions are made, there must be discussion and consensus among the team members.

9. Each member of a team must make the identical investing decision and each student must keep track of the team's investing decisions on her/his template.

10. There is a twofold purpose for every student tracking their team's decisions and portfolio value. One, information on the tracking will be used in a homework assignment to be described later. Two, it reduces calculation errors. Once a team has made decisions for a period, each team member will then separately perform calculations. When completed, students compare with other team members verifying accuracy.

11. At some point the game will finish, but students do not know beforehand after which period the game will end. This reflects real life. Often in life unplanned situations occur when money needs to be accessed. 
The game is then performed for several periods. With each period an explanation is provided for the change in investment price (e.g., employment numbers are stronger than anticipated resulting in an increase in equity prices). At some point, such as after seven rounds, the professor announces that the game is finished. Students then calculate their team's portfolio value. These are then provided to the professor and a winning team is determined.

At this point the professor congratulates the teams on their fine investing results. Most teams will have increased the value of their investment (e.g., if they had \$7,000 to invest, their portfolio is worth more than \$7,000). The technique of DCA is then introduced and demonstrated. Depending on the individual team performance, DCA usually achieves a higher portfolio value. This has a significant impact on students when they see that the active stock picking performance of most teams is inferior to the passive technique of DCA. Additional learning points are discussed with students and a homework assignment is given.

\section{Explanation of Investing Template}

A copy of the template provided to students is shown in Appendix 1. The template could easily be created as a spreadsheet with pre-built formulas for students. However, having students perform their own calculations, rather than automatically calculated by Excel, is worthwhile for their learning and understanding. An Excel "black box" facilitating computations would permit students to participate in the exercise without comprehending how calculations are performed. Explanations for each column are as follows:

\section{Column A: Period number}

\section{Columns B through F Track Cash}

Column B: Beginning cash balance - prior to earnings and stock purchase or sale

Column C: $\quad$ Cash earned from working and allotted for investing (e.g, \$1,000)

Column D: $\quad$ Money available for purchasing equity shares - Columns B + C

Column E: Cash reduction for purchasing equity shares or cash addition from selling equity shares-Columns $\mathrm{G}$ x H x -1

Column F: $\quad$ Ending cash balance for period (this becomes beginning cash balance for next period, Column B) - Columns D + E

\section{Columns G through J Track Equities}

Column G: Equity price for that period (provided by professor at the start of each period)

Column H: Quantity of equity shares to be purchased or sold (team decision)

Column I: $\quad$ Equity share balance-Column I from previous period + Column H of current period

Column J: $\quad$ Value of equities - Columns G x I 


\section{Simulation Example}

Beneath the column headings of Appendix 1, the first four rows provide an example of a four period simulation. This example is explained to students prior to starting their simulation, making sure students have an understanding of the task. Each row is described as follows:

Ex 1: The game begins with $\$ 0$. The investor works and has $\$ 1,000$ to invest. The equity security price is $\$ 20$ and the investor decides to purchase 40 shares, costing a total of $\$ 800$. At the end of period Ex 1, investor has $\$ 200$ in cash and 40 shares worth $\$ 800$.

Ex 2: Investor works and now has $\$ 1,200$ available to invest (beginning cash balance of $\$ 200$ plus an additional $\$ 1,000$ from working). The equity price is $\$ 30$ and the investor sells 15 shares for a total of $\$ 450$. At end of period Ex 2, investor has $\$ 1,650$ in cash and 25 shares worth $\$ 750$.

Ex 3: Investor works and now has $\$ 2,650$ available to invest (beginning cash balance of $\$ 1,650$ plus an additional $\$ 1,000$ from working). The equity price is $\$ 25$ and the investor purchases 60 shares, costing a total of $\$ 1,500$. At the end of period Ex 3, investor has $\$ 1,150$ in cash and 85 shares worth $\$ 2,125$.

Ex 4: Game ends at period 4. Cash balance is $\$ 2,150$ ( $\$ 1,150$ beginning balance plus an additional $\$ 1,000$ from working). Given the equity price of $\$ 28$, the equity value is $\$ 2,380$ ( $\$ 28 \times 85$ shares). Total portfolio value is $\$ 4,530$ ( $\$ 2,150$ cash plus $\$ 2,380$ equity).

\section{Investing by a Student Team}

Once students have an understanding of the game, the simulation begins. Appendix 2 is a completed game template for a student team. The game starts with the professor telling students that the beginning equity price is $\$ 75$. It is noted that this price has no correlation to the equity price in the example game just described (where the equity price ranged from $\$ 20$ and \$30). Students must make an investing decision and may purchase up to 13.33 shares $(\$ 1,000 / \$ 75=13.33)$. The students have no knowledge of future equity prices and all teams must make their investing decisions before the professor provides the next period's equity price. The student team (represented in Appendix 2) made the decision to purchase 11 shares of equity costing a total of $\$ 825$.

Rather than simply giving the next period's equity price, the professor tells students a scenario of an event that will impact the next period's equity price. This adds to the fun of the game and also reinforces or teaches that both financial and world events impact markets. Students are asked to explain in what direction (and why) the equity price will typically respond to a given scenario. For example, prior to giving the equity price for period 2, students might be told that housing starts have just been reported. Students are then asked to explain the impact this might have on the equity price. Once discussed, the professor tells students that housing starts are up, a positive indicator of economic strength, and consequently the equity price has increased to $\$ 80$.

Other possible financial scenarios that could be discussed prior to revealing the equity price for a period include:

1. It is corporate earnings season and reported earnings are either significantly stronger or weaker than anticipated.

2. The Federal Reserve is meeting and will defy conventional thought (no change was expected) by either increasing or decreasing the interest rates by 50 basis points.

3. A terrorist attack has either occurred or been thwarted.

4. It is a presidential election day and either a Democrat or Republican has been elected, one of whom is much more business friendly.

5. The index of consumer sentiment has just been released and it is either stronger or weaker than anticipated.

6. It has just been announced that either tariffs will be imposed on imported steel and aluminum or that a new trade agreements has been established.

For period 2 students are reminded that by working they have earned an additional $\$ 1,000$ for investing. This will be true for each subsequent period. The student team, represented in Appendix 2, 
decides to sell four shares of equity at a price of $\$ 80$. The team now has $\$ 1,495$ in cash and $\$ 560$ in equities (7 shares at $\$ 80$ per share). This cycle repeats itself for each period until the professor announces that the game will end with the next period.

Student team decisions are shown in Appendix 2 for periods 1 through 6. In this particular game, after the students are given the equity price of $\$ 70$ for period 6 , students are informed that this is the last period of the game. That is, students will make decisions for period 6 and then an equity price will be given for period 7. Teams must then "cash out" calculating their team's portfolio value with an additional $\$ 1,000$ from working and the new period 7 equity price. Student engagement level is typically high and so is the anticipation regarding the ending equity price (period 7). Teams heavily invested in equities hope the share price increases while teams holding large cash positions prefer the share price to drop.

Again, a scenario is told that will impact the equity price. A little levity is injected to the game by describing a silly, but not far-fetched, situation that would impact markets. A possible scenario might be either a plague is spreading throughout the world, or all diseases, including cancer, have been eradicated. For this game, the news is amazing. All diseases have been eradicated and consequently the equity price increases to $\$ 85$ ! Upon hearing this, often there are both audible cheers of celebration and groans of disappointment among students. It can be humorously observed to the class that some students are disappointed that all diseases in the world have been eliminated! Although only a game, it can be a good learning point regarding the proper (and improper) pursuit of wealth.

Each team then calculates their portfolio values. The team represented in Appendix 2 has an ending portfolio balance of $\$ 8,110$, comprised of a cash balance of $\$ 4,965$ and equities valued at $\$ 3,145$. The professor then calls on each team for their ending portfolio value and records it for the class to see and a winning team is determined. Most teams will perform admirably, increasing their portfolio value to an amount greater than the $\$ 7,000$ that was earned and available for investing.

\section{A Note about Equity Prices and Number of Periods}

The equity prices in this simulation work nicely for student learning and usually result in dollar-cost averaging performing better than student teams. The equity prices realistically represent movements in the market. For example, although short term movements in equity prices are unpredictable, over the long run markets and equity prices have a tendency to move up (increase in value). Burton Malkiel describes this as a random walk (Malkiel, 2019). The equity prices used in this simulation reflect this phenomenon of unpredictable variability in the short term with a long term increase in price (started at $\$ 75$ and ended at \$85). Other equity prices could be used.

Students rarely question the validity of the professor's predetermined equity prices for the simulation. However, a permutation could be done to incorporate dynamic randomness. Equity prices could be determined real-time during class via a random number generator such as Excel or dice. Howard, in a classroom exercise showing the power of diversification, uses dice to simulate returns on an investment (Howard, 2016). Similarly, dice could be used in a similar fashion to determine equity prices.

Seven periods work well for students. It allows student interest to mount, yet does not exhaust students' limited attention span. The game could be extended for more rounds, but the risk is that students may begin to lose interest while any marginal learning for students would be small.

An important component is that students not be told beforehand the specific number of periods in the simulation. Based on the template having 10 rows for periods, students should assume that there will be a maximum of ten periods in the game, but potentially less. This provides an element of unexpectedness for students and replicates the unknowingness of real life. At the end of the game, students are told a life event has happened that requires the student to cash out after the seventh period. This life event might be the student is returning to graduate school, a family member requires major medical care and needs monetary assistance, or any other possible situation requiring significant financial resources. 


\section{DOLLAR-COST AVERAGING}

After the simulation is complete and a winning team recognized, investing strategies of teams are discussed. Eventually the discussion leads to the professor explaining to students that although students may think their lives are currently very busy, their future lives are going to be even more hectic and will only get more eventful as life progresses. Balancing a career and family will be challenging. There will be work, household chores, shopping, hobbies, a social life, a significant other, children (piano lessons, soccer games, doctor appointments, etc,), and aging parents that will require care. With all the demands on their life, there will be minimal residual time that can be devoted to investing. Fortunately, there is an investment strategy that does not require significant time, it is easy to understand, and the performance is good - dollar-cost averaging (DCA).

It is explained to students that DCA is a simple "close your eyes" approach to investing. Do not look at or monitor equity prices, simply invest all money in the market purchasing equities. Each period, when $\$ 1,000$ is available for investing, purchase equities with the entire $\$ 1,000$. A completed template for DCA, using the identical equity prices the students just encountered in the simulation, is shown to the students and is described (Appendix 3).

Appendix 3 demonstrates $\$ 1,000$ of equities being purchased every period with $\$ 0$ cash remaining at the end of each period. This DCA approach yields an ending equity value of $\$ 9,231$. Compared with the student team performance in Table 2, DCA is $\$ 1,121$ (or 13.8\%) greater. This is common. In most cases the performance of DCA will be superior to the performance of student teams.

Students are intrigued and are ripe for learning more about DCA. At least three learning opportunities are available for discussion. First, with DCA the average equity purchase price will always be equal to or lower than the average equity price over the investing periods. Second, DCA purchases a greater number of shares when equity prices are low relative to when equity prices are high. Third, although DCA is easy to implement, it requires discipline.

A major attraction of DCA is that, over time, the average purchase price will always be lower than (or equal to) the average share price. That is, if over a period of years an investment had an average price of $\mathrm{X}$, when DCA is used to purchase the investment, the average purchase price will always be less than or equal to $\mathrm{X}$. There is never an exception. The calculations of these two numbers, average share price and average purchase price, are not difficult. Most students readily understand that the average equity price over the seven periods is obtained by adding the equity prices for each period and dividing this summation by 7 . This calculation, as shown on Appendix 3, results in an average equity price of $\$ 67.43$.

Although straightforward, computing the average purchase price per share is a bit more challenging for some students to grasp. Intuitively, it is simply the total amount paid $(\$ 7,000)$ divided by the number shares purchased (108.599 shares). In other words, if $\$ 7,000$ is spent to purchase 108.599 shares, the average price paid per share is $\$ 64.46$ per share. This calculation is also shown at the bottom of Appendix 3. As will always be the result, the average purchase price $(\$ 64.46)$ is less than the average share price (\$67.43).

Why is it that DCA performs so well? Instinctively, it is because when share prices are relatively low, DCA purchases more shares and when share prices are relatively high, DCA purchases fewer shares. This is demonstrated to students by comparing periods 2 and 4 . In period 2, the equity price was higher than period 4 (\$80 compared with $\$ 45)$. Consequently, DCA purchased less shares in period 2 (12.5 shares) compared with period 4 (22.222 shares). This is the result of investing a fixed amount each period. When a share price is high, a fixed dollar amount will purchase fewer shares than when the equity price is low. DCA adheres to the adage buy low (and sell high).

Students need to be aware that although DCA is apparently simple, its most challenging aspect is that it requires discipline. An investor must not deviate from the DCA strategy of strategically purchasing the same dollar amount of equities; otherwise, the intrinsic benefit of DCA is lost. This appears easy, but it often contrasts with one's irrational emotions. Improper inclinations and tendencies are to sell shares (or invest less) during down markets and purchase (invest more) as markets are increasing (Hirt and Block, 2011). When stocks are in the midst of a bull market, roaring upwards and making great gains, 
emotionally one wants to invest even more than the DCA amount. Contrarily, when the market is plummeting, one wants to stop buying and instead sell equities. Students are warned that they must resist these imprudent natural urges of buying more when prices are high and less when prices are low. DCA self-corrects negative emotional behaviors with fixed dollar amount purchases, regardless of short-term market conditions and fluctuations. Moreover, in the long-run, DCA not only restrains negative behavior, it enhances investing. Maintaining a DCA strategy assures that more shares are purchased at low prices and less shares at high prices. As Warren Buffett has expressed "You want to be greedy when others are fearful. You want to be fearful when others are greedy. It's that simple." (Buffett, 2008)

\section{HOMEWORK FOR STUDENTS-HOW GOOD IS DCA PERFORMANCE?}

Even though DCA performs superior to all or most of the student teams, it is not optimal. Indeed, through stock picking and timing, one could reach a portfolio value greater than the $\$ 9,231$ achieved with DCA. To better evaluate the performance of DCA, it would be useful to know the best and worst case scenarios of the equity picking simulation. That is, if a team had bought and sold equities at the worst times, what would be the value of the portfolio at the game's end? In contrast, if a team had bought and sold equities at the most opportune times, what would be the portfolio's value at the game's end? DCA would then fall somewhere between these two extremes.

Determining an upper bound (optimal portfolio value) and a lower bound (worst portfolio value), then comparing where within this range (optimal to worst) DCA falls is helpful in evaluating DCA's performance. Identifying DCA's performance as nearer the bottom, middle, or top of this range helps to assess DCA and the practicality of implementing DCA. For example, if DCA's performance is much closer to the lower bound (worst case) than the upper bound (best case), one might rightfully be skeptical of implementing DCA as an investing strategy. If when deviating from DCA the upside potential is great (high reward) and the downside risk is minimal (low risk), then a rational decision might be to reject DCA and attempt to do better by actively picking when to buy and sell. Conversely, if the performance of DCA is closer to the optimal upper bound, a rational decision would be to implement DCA.

Students are given the homework assignment of determining the best and worst case scenarios and then to evaluate the performance of DCA based on these upper and lower bounds. Students are not told how to determine the highest and lowest possible portfolio balances, only that heuristics must be utilized, that when followed, will produce the best and worst case outcomes. Students, typically unfamiliar with the term heuristic, are told that a heuristic is simply a procedure to follow when solving a problem. The students must, then as homework, grapple with determining and implementing the correct heuristic for the best and worst case investing scenarios. Additional blank investing templates are made available to students to complete the assignment.

In the subsequent class session the homework assignment is collected and discussed. Some students (usually half or less of the class) have determined the proper heuristics. A best case (optimal) outcome and a worst case outcome are both shown and explained to students. The underlying concept for the heuristics, both the best and worst case, is that an investor needs to be completely in, or out, of equities at all times. That is, each period the investor must determine whether to be 100 percent invested in equities with $\$ 0$ in cash, or 100 percent in cash with no equities.

The best case optimal solution is shown and explained to students (Appendix 4). The proper heuristic rule is to compare the current period's equity price with next period's equity price. If next period's equity price is greater than the current equity price, the investor should be completely invested in equities with $\$ 0$ in cash. When the equity price is going up, it is an opportunity to increase the portfolio value. Therefore, all money should be invested in equities. Conversely, if the next period's equity price is lower than the current period's equity price, the investor should be completely in cash and have $\$ 0$ invested in equities. Otherwise, the portfolio value would decrease. This heuristic is repeated each period. Adhering to this heuristic has the investor fully invested in equities in Periods $1,4,5$, and 6 . The optimal best portfolio balance would be $\$ 11,499$. No higher value is possible. 
The worst case solution is shown in Appendix 5. Again, the heuristic has the investor either fully invested in equities, with $\$ 0$ in cash, or fully in cash, with $\$ 0$ in equities. As before, a comparison is made between the current period's equity price with the next period's equity price. This time, if the price is increasing, the investor should be fully in cash with $\$ 0$ invested in equities. When the price is decreasing, the investor should be fully invested in equities with $\$ 0$ in equities. Appendix 5 indicates that adherence to this heuristic would have the investor fully investing in equities in only Periods 2 and 3. The worst solution would be $\$ 5,828$. A lower portfolio balance is not possible.

Now that an optimal solution $(\$ 11,499)$ and a worst case solution $(\$ 5,828)$ have been determined, the results of a DCA strategy can be further critiqued. DCA resulted in a portfolio balance of $\$ 9,213$. Comparing with best and worst possible (Table 1), DCA is closer to the optimal solution than the worst solution. Granted, this is an isolated instance, and the positioning of DCA will vary depending on the situation, but it bodes well for DCA being an attractive investing strategy. Although DCA is not perfect, it is simple to implement, requires minimal time, and the results are very good.

TABLE 1

COMPARISON OF BEST, WORST, STUDENT TEAM, AND DOLLAR-COST AVERAGING

\begin{tabular}{|l|r|r|r|}
\hline \multicolumn{1}{|c|}{ Comparison Groups } & \multicolumn{1}{c|}{$\begin{array}{c}\text { Ending Portfolio } \\
\text { Value }\end{array}$} & $\begin{array}{c}\text { Dollar Difference } \\
\text { from DCA }\end{array}$ & $\begin{array}{c}\text { Ending Value as a } \\
\text { Percent of Optimal }\end{array}$ \\
\hline Best (Optimal) & $\$ 11,499$ & $\$ 2,286$ & $100 \%$ \\
\hline DCA & $\$ 9,213$ & $\$ 0$ & $80 \%$ \\
\hline Midpoint Best \& Worst & $\$ 8,664$ & $(\$ 549)$ & $75 \%$ \\
\hline Student Team & $\$ 8,110$ & $(\$ 1,103)$ & $51 \%$ \\
\hline Worst & $\$ 5,828$ & $(\$ 3,385)$ & \\
\hline
\end{tabular}

\section{CONCLUSION}

More than ever it is vital that people understand and are able invest for their future. Defined benefit retirement plans are fading and rapidly becoming a relic of the past. Defined contribution retirement plans in the form of 401(k), 403(b), and 457 plans dominate and their growth will continue to increase. As such, an understanding of investing and investing strategies is imperative. A simple and effective investing strategy, that could prove beneficial to many investors, is dollar-cost averaging (DCA). Finance courses are an ideal opportunity to educate students on DCA and its advantages.

This paper describes a team based simulation that realistically simulates investing for retirement and exposes students to DCA. Teams actively trade equities and compete for the highest portfolio balance. DCA is then introduced and the performance of DCA is compared with student team performance. In most instances, student teams perform well, but their portfolio balances are inferior to that of DCA. As an extension and further evaluation of DCA, students are required to determine the worst and optimal possible outcome for the investing simulation. DCA is then evaluated with these upper and lower bounds and it is found that DCA is closer to the optimal portfolio balance than the worst portfolio balance. 


\section{REFERENCES}

Buffett, W. (2008). Buy American. I Am. The New York Times. Retrieved from https:/www.nytimes.com/2008/10/17/opinion/17buffett.html.

Campbell, T. (2016). Putting the "Real" in Real Options: A Board Game Approach. Journal of Financial Education, 42(1/2), 102-115.

Cebula, R., \& Toma, M. (2002). The Effect of Classroom Games on Student Learning and Professor Evaluations. Journal of Economics and Finance Education, 1(2), 1-10.

Hirt, G., \& Block, S. (2011). Fundamentals of Investment Management, $10^{\text {th }}$ edition, McGraw-Hill Education.

Howard, B., (2016). The Power of Diversification: A Classroom Experience. Journal of Financial Education, 42(3/4), 263-275.

Kessler, G. (2014). Do 10,000 Baby Boomers Retire Every Day? The Washington Post. Retrieved from https:/www.washingtonpost.com/news/fact-checker/wp/2014/07/24/do-10000-baby-boomersretire-every-day/?utm term $=.1 \mathrm{abc} 765 \mathrm{f} 44 \mathrm{~d} 4$,

Malkiel, B., (2019). A Random Walk Down Wall Street: The Time-tested Strategy for Successful Investing. New York: W.W. Norton.

McDonald, M. (2017). Hedge Fund Manager Who Lost Bet with Buffett Sours on Long/Short Equity. Bloomberg Markets. November 10, 2017. Retrieved from https://www.bloomberg.com/news/articles/2017-11-10/hedge-fund-manager-trailing-buffettsours-on-long-short-strategy.

Payne, J., \& Tanner, G., (2011). Experiential Learning and Finance: A Hands-on Approach to Financial Modeling. Journal of Financial Education, 37(3/4), 82-100.

Porter, S., (2017). Why 'Father of the 401(k)' Says He Regrets Pushing the Retirement Plan. The Christian Science Monitor. Retrieved from https://www.csmonitor.com/Business/2017/0104/Why-Father-of-the-401-k-says-he-regretspushing-the-retirement-plan.

Rattner, S., (2018). The Market Isn't Bullish for Everyone. The New York Times. Retrieved from https://www.nytimes.com/2018/01/22/opinion/bull-stock-market.html.

Seaton, L., \& Boyd, M. (2008). The Effective Use of Simulations in Business Courses. Academy of Education Leadership Journal, 12(1), 107-118.

Sorkin, A. (2017). Buffett Asks Big Money: Why Pay High Fees? The New York Times. Retrieved from https://www.nytimes.com/2017/02/27/business/dealbook/buffett-asks-big-money-why-pay-highfees.html.

Thaler, R. (2015). Misbehaving: The Making of Behavioral Economics. New York: W.W. Norton \& Company Ltd.

Wyatt, E. (2019). John C. Bogle, Founder of Financial Giant Vanguard, Is Dead at 89. The New York Times. Retrieved from https://www.nytimes.com/2019/01/16/obituaries/john-bogle-vanguarddead.html. 


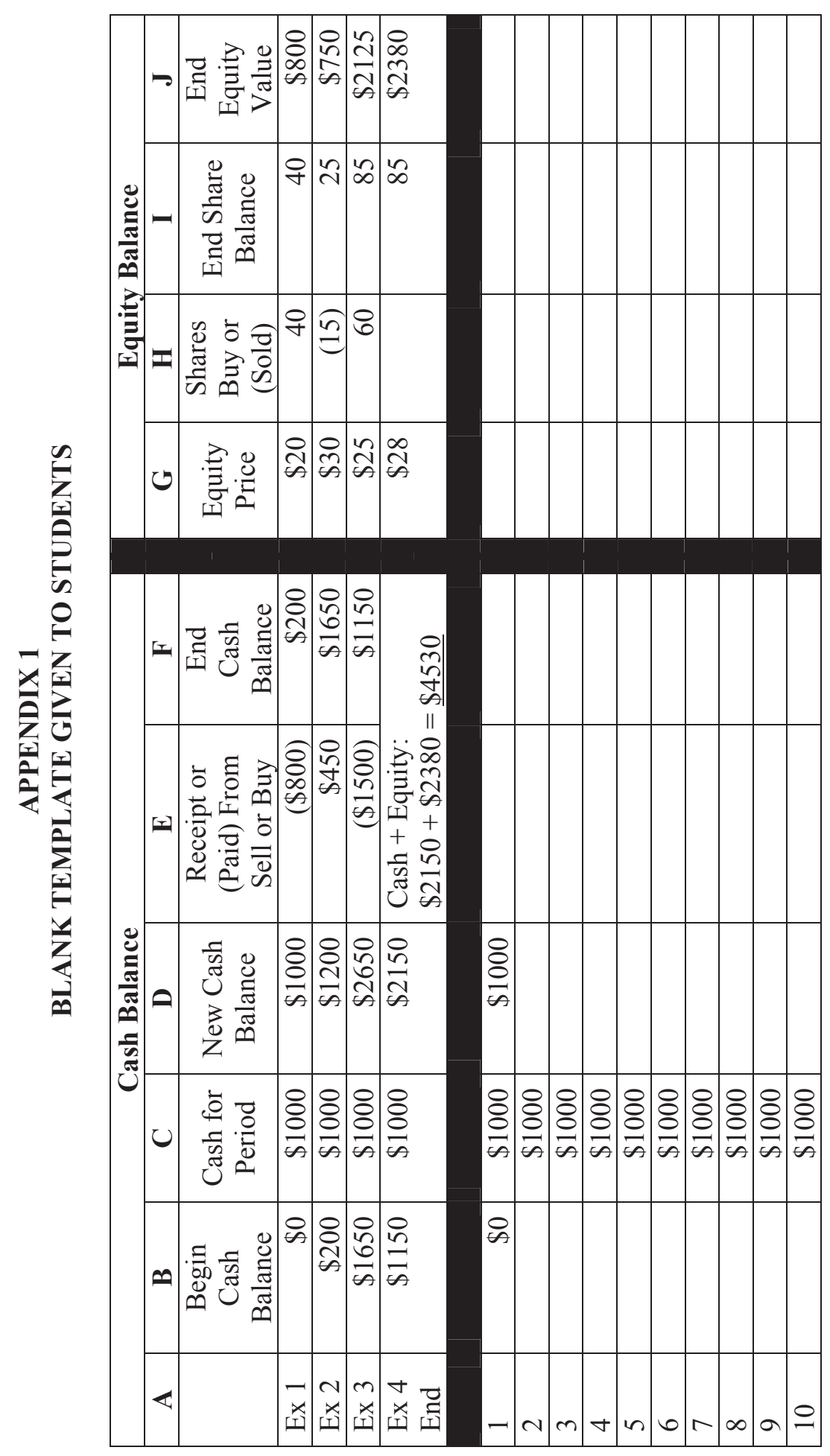

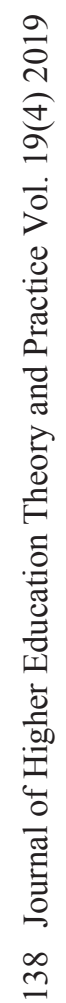




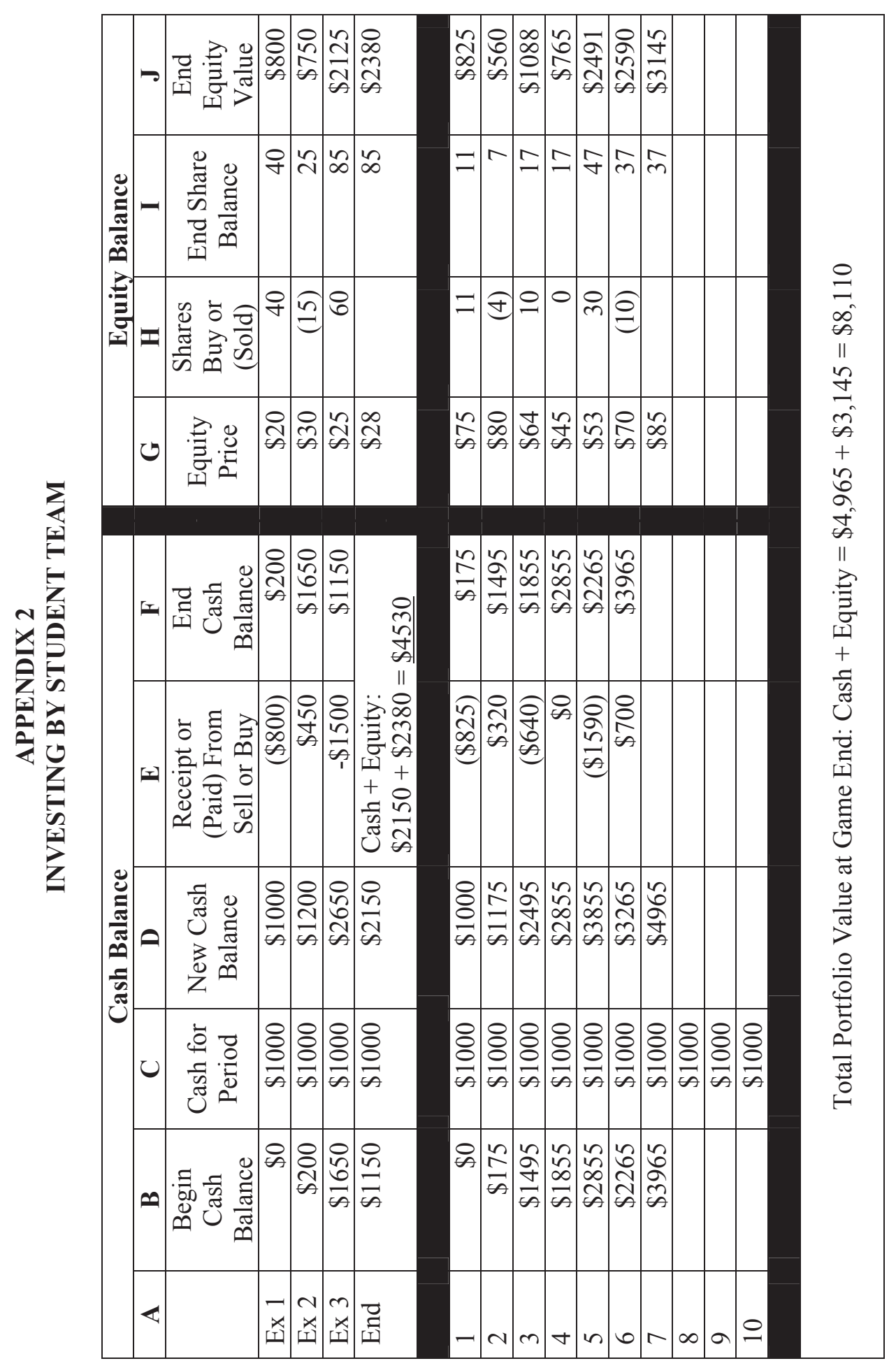

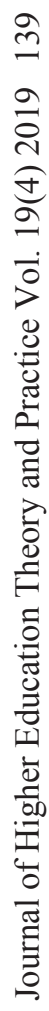




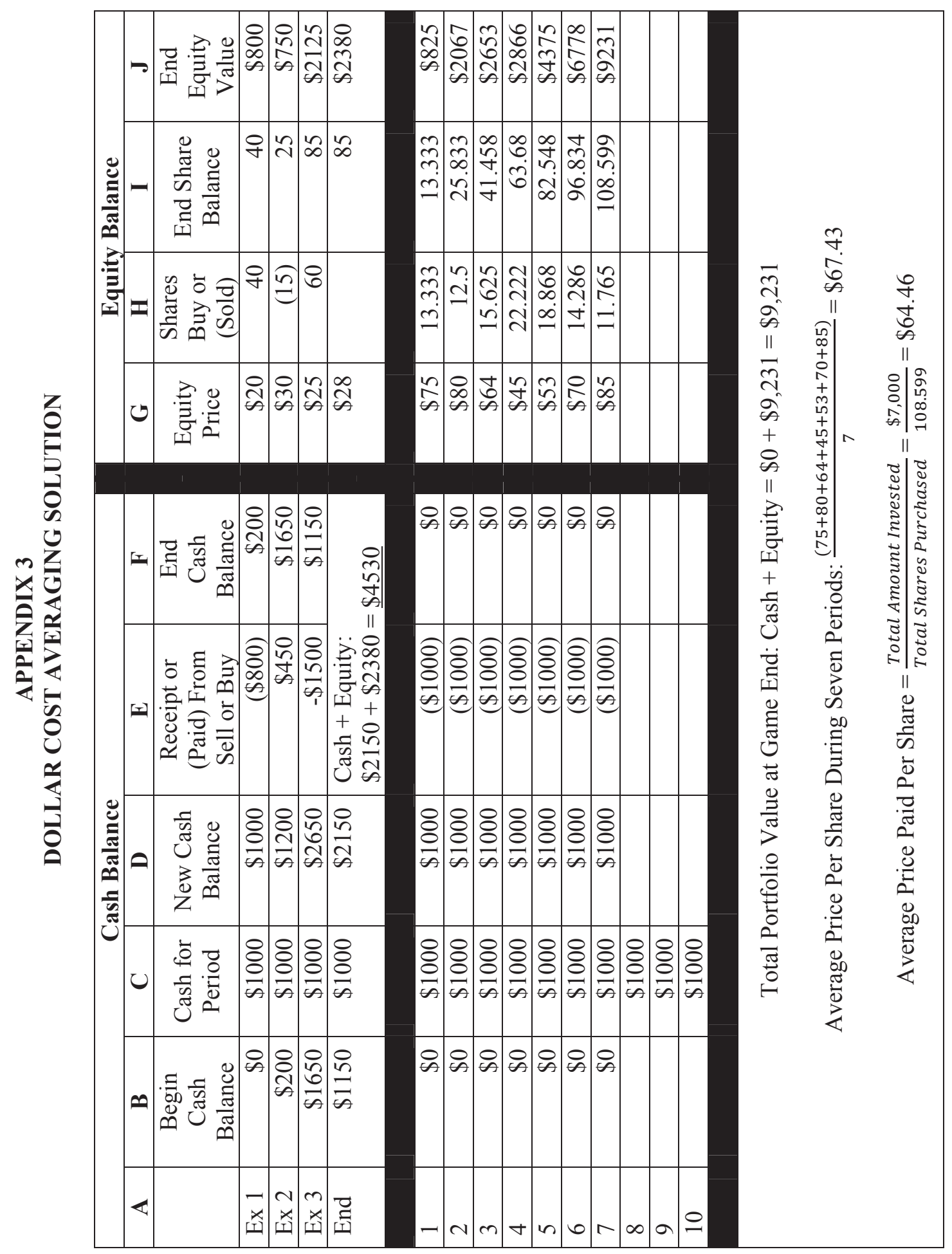

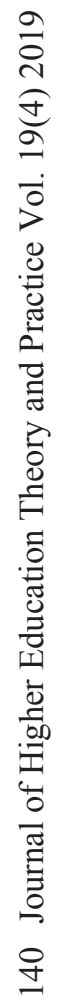




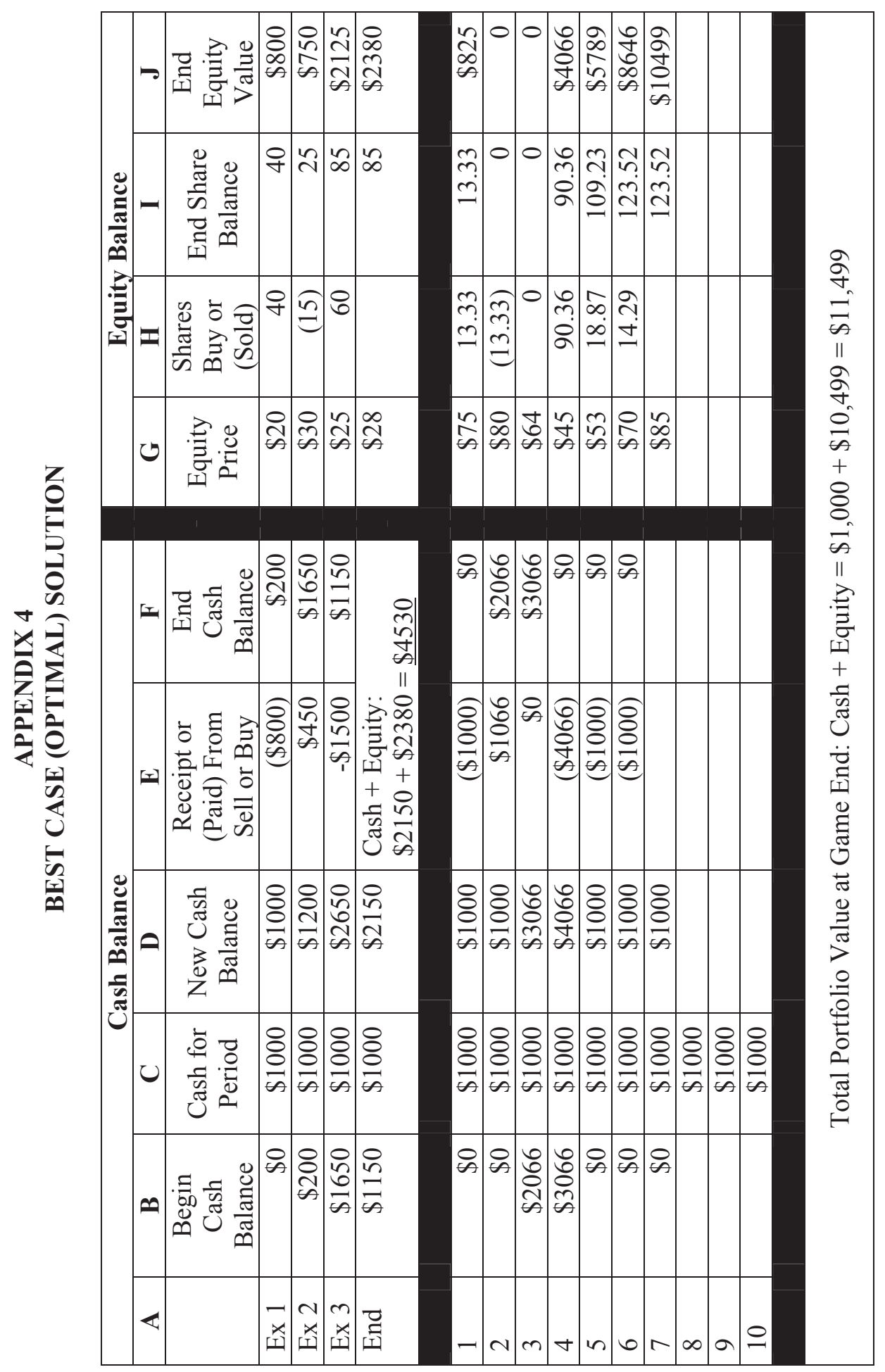

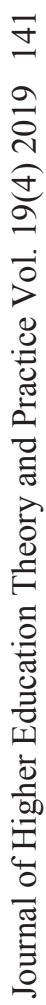




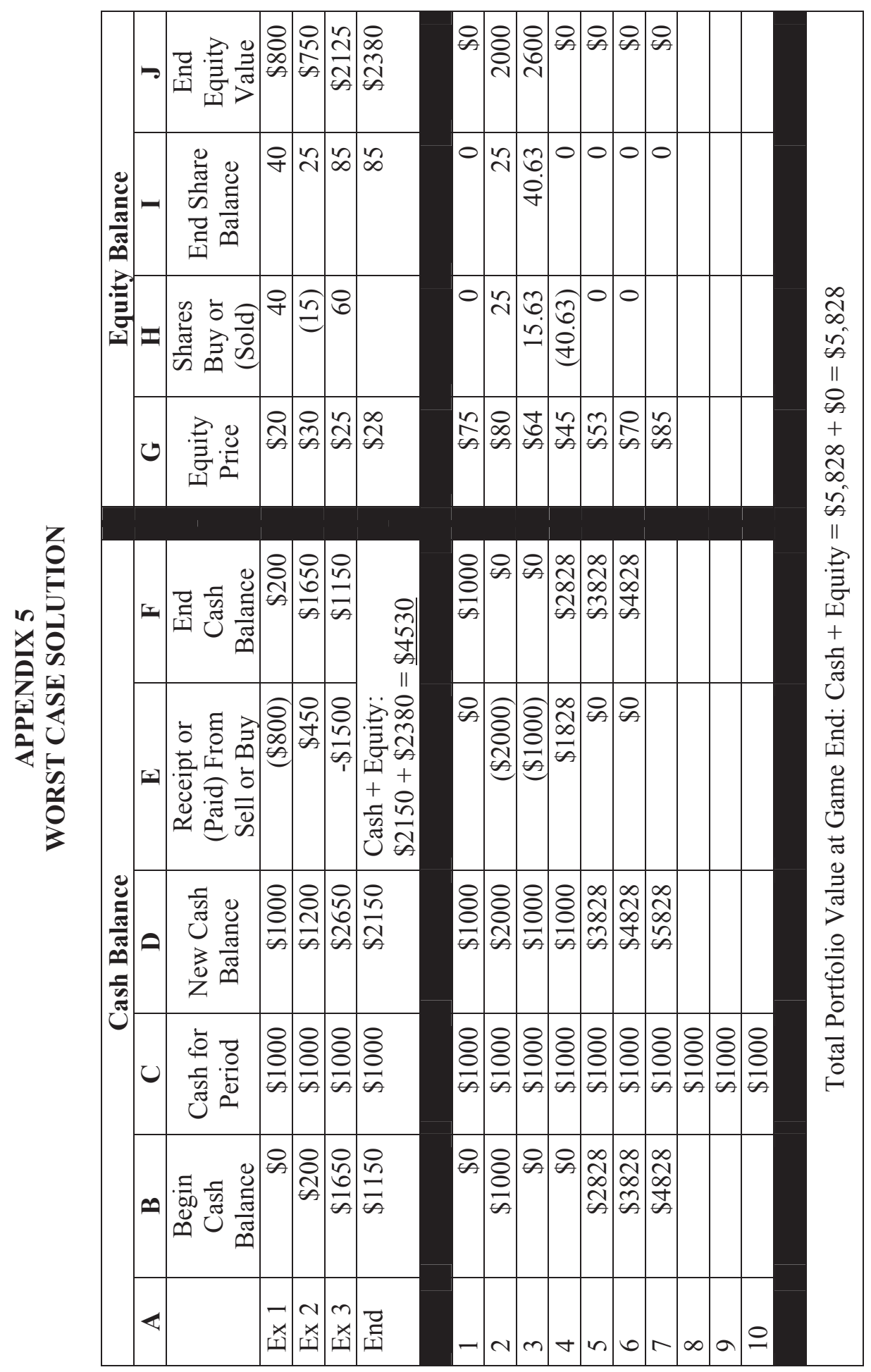

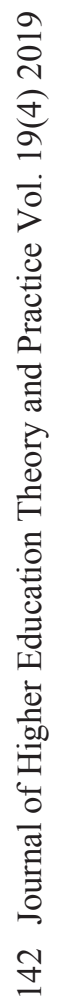

